Daniel Schulze*

\title{
The Passive Gaze and Hyper-Immunised Spectators: The Politics of Theatrical Live- Broadcasting
}

DOI $10.1515 /$ jcde-2015-0024

Abstract: This article investigates theatrical livecasting. It argues that live broadcasts by the National Theatre are closer to cinema than to a theatre performance, as the camera shapes the performance and renders the audience passive. Secondly, it analyses Forced Entertainment's live streams of their durational works and the audience's involvement through Twitter. It questions the level of involvement and meaningful communication, and finds that such broadcasts must be viewed as artworks in their own right. It finally calls for more research into livecasting and audience involvement, as this phenomenon is likely to increase.

\section{Introduction}

In September 2014, Berlin's cultural secretary, Tim Renner, demanded that all publicly funded theatre productions be broadcast for free in order to make theatre more accessible for a broad audience. This demand has been discussed controversially in German papers (cf. Stadelmaier and Tobler). However, broadcasting of theatrical performances already happens frequently in a number of European countries. Live broadcasts such as Robert Wilson/Philip Glass' Einstein on the Beach (Paris, 2014) are highly successful. The National Theatre in London (NT) regularly broadcasts its shows live to cinemas all over Europe-for paying audiences. While the question of revenue is crucial for theatres (free streaming or cinema broadcast?), broadcasting to cinemas or home computers also raises some interesting questions regarding politics and spectatorship.

This paper takes a look at two kinds of theatrical broadcasts. It will first discuss the NT's live series by the examples of King Lear (2014) and Frankenstein (2014). It will argue that in terms of politics, audiences are condemned to absolute passivity, they are deprived of their voice in the form of booing, heckling or cheering. Audiences become passive spectators, who-in Walter Benjamin's sense-are passive consumers of the camera's gaze. The aesthetics

*Corresponding author: Daniel Schulze, E-Mail: d.schulze@uni-wuerzburg.de 
of reception of such an event are consequently closer to film than to theatre. Secondly, the paper will discuss Forced Entertainment's recent broadcasts of its major durational performances: And on the Thousandth Night (Lisbon, 2014), Speak Bitterness (Berlin 2014), and Quizoola24! (Sheffield 2014). These performances create a participatory climate as they always come with a Twitter hash tag that usually sparks lively debate. Spectators are enabled to comment on the events and enter directly into an exchange with other viewers in remote locations-they become active, emancipated spectators in Rancière's sense. They, however, miss out on the corporeal co-presence of the performance and are consequently still hyper-immunised-to use Alan Read's turn of phrase-in the privacy of their own home, but they are no longer passive. Whether tweeting, however, can be considered a form of social exchange remains an open question. Aesthetically, the perception of such performances must necessarily be different, and, at times, inferior to the one in a performance space. When performances are viewed on a tiny laptop screen and the spectator is constantly checking Twitter on the side, the performance itself becomes only one part of the entire mediated experience. Consequently, this form of livecasting must be regarded as an entirely independent work of art that demands further reserach.

\section{Livecasting: Beyond the Fifth Wall}

While broadcasting theatrical events live has become more common and successful over the past ten years, it is noteworthy that there are earlier attempts at this format such as for instance Christoph Schlingensief's broadcast of his container performance in Vienna in 2000 (cf. Tobler), or live broadcasts by Hampstead theatre or of the York Mystery plays (cf. Gardner "Top Ten"). Interestingly, however, theatrical live broadcasts have received little academic attention so far, although "they pose a series of challenges to many traditional theories in fields such as cinema studies, theatre and performance studies and television studies" (Barker 2). Not even the nomenclature is fixed so far: broadcast performances come under the labels of "simulcast," "cinema livecast" or "beamed live performances" (Barker 2). For the purpose of this paper, following Barker, the term 'livecast' will be used to denote all performances that are broadcast live, whether they be seen in a cinema or on a device at home. Livecasting has seen a remarkable rise in popularity over the last decade. Between 2007 and 2010 the share of livecasts in the segment of 'alternative content' (anything but films) in cinemas more than doubled from $26 \%$ to over $54.9 \%$ (cf. Barker 40). The concurrent decline in alternative content that was not live is indicative of the audience's 
preference for live events (cf. Barker 40). The rise of livecasting is, however, not only due to shifting audience-preferences, but also to technical advancements and, crucially, to economic factors. Barker holds that it was the Metropolitan Opera's director, Peter Gelb, who created the successful format as it is known today. In 2006, when the Met was nearly bankrupt, Gelb sought to make it profitable again, and at the same time to broaden and rejuvenate its audience. He succeeded, generating revenues of $\$ 18$ million a year out of livecasts in their second season (cf. Barker 1-2). Similarly profitable considerations are at work at the NT. "We all know that NT Live is becoming increasingly crucial to the National Theatre in terms of audience reach and income" (Gardner, "Tweet Bitterness"). While the question of revenue is highly interesting, it will not be the centre of this paper, ${ }^{1}$ which will rather focus on the aesthetics and most importantly the politics of livecasting.

Livecasting has been criticised fiercely on both grounds. The general argument runs along the lines of a lack of agency in any way (booing, heckling, cheering etc.) and an aesthetic reduction through the camera.

Certainly the experience is simultaneous with the event. But there is no physical copresence. Audience responses cannot be heard by performers. There can be no interaction. In between audience and performance comes a whole apparatus of capture, with technical, professional and aesthetic choices pre-formed for audiences. Yet in many ways, audiences at livecasts do value their as-liveness. (Barker 40)

In the opinion of some, a recorded event that includes cuts and zooms will not only alter the experience of the audience but will also change the performance itself. "The camera may start to tease-out thematic and dramatic nuances that are inaccessible to those present in the flesh; so too, a growing tendency for subtle facial acting and restrained vocals sits uncomfortably with the demands of large auditoria” (cf. Dobson). In the NT's livecasts of King Lear and Frankenstein, seeing the facial expression of the actors up close certainly provides a different aesthetic experience than in the theatre because not even in the front seats is a

1 The question of revenue, or rather, the 'economic impossibility' of theatre has been a longstanding problem for the performing arts in times of dwindling subsidies and ever increasing costs (cf. Kotler 4). The biggest problem of most performing arts is however their inherent lack of productivity gains and economies of scale that would occur in any other industry (cf. Kotler 1011). Any play, opera or symphony simply takes a certain amount of people to perform which can usually not be cut down easily, at the same time, auditoria cannot be expanded endlessly. Livecasting might ameliorate this situation as it is able to create ever decreasing marginal costs by serving a potentially ever expanding consumer base. 
spectator so close to the actors as to perceive every batting of an eyelid. Whether actors however consciously change their acting style for the camera remains unclear. Actors in both performances never directly interacted with the camera, which Dobson also acknowledges is the case in most livecasts. Much harder to rebut is the argument that spectators are deprived of their freedom of gaze and become passive consumers of the camera's gaze. This argument has most succinctly been phrased by Stadelmaier who claims that viewers in front of a screen are objects, spectators in the theatre are subjects. Essentially, this is a repetition of Walter Benjamin's argument from The Work of Art in the Age of Mechanical Reproduction:

\begin{abstract}
The artistic performance of the stage actor [i.e. what he or she does artistically] is presented to the audience by the actor in person; of that there is no doubt. The artistic performance of the screen actor, on the other hand, is presented to the audience via a piece of equipment, a film camera. The latter has two consequences. [...] Guided by its operator, the camera comments on the performance continously. [...] The second consequence is that the screen actor, by not presenting his performance to the audience in person, is deprived of the possibility open to the stage actor of adapting that performance to the audience as the show goes on. (17-18)
\end{abstract}

The camera disturbs both, the interaction between performer and spectator, and it also shapes the performance by selecting angles, zooms, and showing one thing and not another. This is highly problematic for performances that are explicitly contemplative and experimental, in which plot and action play a minor role, such as for instance Robert Wilson and Philip Glass' opera Einstein on the Beach, which was livecast in 2014 (cf. Tobler). Any camera work in this case diminishes the performance because it prioritises and thus robs the viewer of their aesthetic choice and personal contemplation. Similar mechanisms are at work in the NT's livecasts. In Frankenstein, the camera frequently zoomed onto actors' faces or simply focussed on one bit of the stage, blanking out another. This was particularly significant in the first few minutes in which the hundreds of light bulbs that dangled from the ceiling played a prominent role. Every time the lights flashed up, the camera took a direct shot from underneath the ceiling; a perspective that is impossible for a spectator in the theatre. Furthermore, the flashing up of the lights, as the creature was born, always came with a direct cut to the lights that were almost blinding in their intensity. As a viewer in the cinema there was no choice to look upon the lights longer and contemplate them, neither was there a chance to keep the eyes fixed on the stage. Whether this is good or bad remains up to debate, what is clear is that the spectator, who is already largely relegated to passivity, is finally robbed of their last visual choices. They become passive consumers of a uniform good. The aesthetics of livecasting are consequently closer to film than to theatre, the only thing that sets 
them apart is liveness. ${ }^{2}$ A case can also be made in favour of livecasting. While rendering the spectator a passive cinemagoer, it makes the performances accessible to a wider audience, say in different countries and social segments different from the narrow, theatregoing sample of the population. Livecasting consequently promotes inclusivity. Dobson is critical of such claims-which will, according to him, however find easy acceptance in academia-when he maintains that ticket prices are high, even in cinemas, and he believes that lower ticket prices, offers, or performances in different cities might achieve more in this respect (cf. Dobson). In his opinion, livecasts do both, they invite in and proclaim inclusivity and, at the same time, establish a sharp dividing line between the audience in the auditorium and the audience in the cinema. The audience in the cinema may feel that they are part of the event and receive the performance just like the audience in the theatre, but in fact they are not beyond the fourth wall but beyond the 'fifth wall.' They have no means of reacting to the performance or interacting, they are not part of the physical collective. Their experience is mediated by cameras and microphones and cannot claim immediacy. Thus the event becomes a projection of the wish to be part of the event and of partaking in a cultural exercise. It mirrors one's own desire of social inclusion, while upholding a dividing line between the spectator who is there and might even be captured on camera and the faceless, anonymous viewer in a cinema somewhere else. "Our auditorium is a pale reflection of theirs. They belong whilst we peer in. So too they are a literal, fixed part of the broadcast and subsequent repeats; they become signifiers in the symbolic nexus, a meaningful part of a glamorous cinematic narrative" (Dobson). Consequently, livecasting establishes politics of seeming inclusion, while sacrificing the aesthetic liberty of the theatrical spectator. It is a film that pretends to be more than it is and promises more than it can fulfil.

\section{3 “How do You Clap Over Twitter?" Forced Entertainment's Livecasts}

Matters are different with the livecasts of Forced Entertainment's (FE) major durational works, which took place in 2014. All of them were accessible online for

2 The highly interesting aspect of 'liveness' cannot be discussed here at length. For a versatile discussion of 'liveness' with regards to livecasting, see Barker 39-60. He notes that liveness should always be regarded from a multidisciplinary angle, as many disciplines have made fruitful advances on the subject but also employ their terminology. He for instance names Virtual Presence Studies or Sports Studies as examples. 
free in most countries around the world. Furthermore, all performances came with a Twitter hash tag that enabled spectators to comment on the performance as they watched it. Lyn Gardner made the livecast of Speak Bitterness number five in her top ten theatre events of 2014 (cf. “Top Ten”). FE’s Tim Etchells saw the possibility of watching the performance everywhere as adding to the work:

The work, streamed like TV or radio or streamed music and video, can be followed on the phone, at the dinner table, accompanying people's lives as they do other things. Somehow this additional porousness works for it, creating odd juxtapositions and parallel tracks, even as it tries to suck people deeper into watching it. (Etchells)

Similarly pleased was Gardner who was happy that she was "able to watch it at home while eating my supper rather than sitting in a theatre; it was refreshing not to have to get on a tube and train to return home afterwards when I was feeling tired” (Gardner, "Bitterness"). The audience consequently encompassed not only the people at the venue but thousands of people in various locations with various degrees of investment who were all able to freely consume the performance for however long and under which circumstances they liked, and comment on it via Twitter. This of course raises resonances of Rancière's emancipated spectator who overcomes the binary of watching/passive and acting/active (cf. Emancipated 12). While Rancière does not necessarily have spectators in mind who actively comment (he is rather concerned with spectators and performers in ontological terms), he stresses that emancipation is not limited to the theatrical space but begins everywhere: we are all spectators "who all the time link what we see to what we have seen and said, done and dreamed. [...] Every spectator is already an actor in her story; every actor, every man of action, is the spectator of the same story" (17). His prerequisite for emancipation is a state of total equality (cf. Rancière 79). Twitter therefore seems an ideal place to start as it is free, accessible and anyone can voice their thoughts. But do they? The vast majority of the tweets for Quizoola24 (\#Quizoola24) and Speak Bitterness (\#FESpeaklive) are repetitions of phrases of the performance. Indeed, there was very little discussion of any sort going on on Twitter. If people did not simply repeat phrases from the performance, they mostly stated where and with whom they watched it or tweeted images from their living room (cf. \#Quizzola24!). If they did commented on the performance, the statements went almost always unanswered-in short, there was no dialogue. Twitter appears to be the medium of statements more than of discussions. Granted, the 140 characters that Twitter allows its users do not lend themselves to lengthy and open debate. However, I would argue that the vast majority of the Twitter users were not seeking any meaningful exchange but only had the aim to be recognised. Essentially, this is an almost exhibitionist pleasure 
that seeks to display one's own partaking in a cultural exercise. The statements and photos from living rooms proclaim that one is part of the cultural collective which seeks out theatrical events. It is a similar idea of taking part in a cultural exercise as in the NT's livecasts which surfaces here. Moreover, the ostentatious display of one's involvement in the performance begs, if not for a response, at least for a multitude of users to perceive this statement. A message needs to be read and then makes the speaker part of the collective even if no dialogue takes place. What viewers were seeking-and many tweeted about this after the performance-was a form of visibility in a community.

Lyn Gardner found that "it's possible to have a communal experience watching theatre in your own home" (Gardner, "Bitterness"). While she acknowledged that watching a livecast at home was not the same thing as being in the theatre, she maintained that

it can be a hugely rewarding and different way of experiencing a show. One that can be as equally a communal experience via Twitter as actually being in the auditorium. In some senses an even more communal experience because you can be in constant dialogue with other people while watching the stream too. ("Bitterness")

Andrew Haydon had similar feelings: "During Quizoola I variously smoked indoors, slept, tweeted with other people watching around the world, and took loo breaks whenever I fancied-and didn't affect the experience of anyone else watching one iota by doing so" (Haydon). Gardner and Haydon are by no means examples of convenience or the only ones to voice such feelings (cf. \#FESpeaklive). It seems that many of the viewers were quite happy being at home, tweeting, not getting socially involved with anyone in a public place.

This state of affairs can be understood as 'immunisation,' as proffered by Alan Read who claims that audiences frequently do not want the fourth wall to be broken, and in fact enjoy the sensation of watching without being seen or implicated in a discourse: "The 'immunisatory logic of theatre' [...] is the contract we make as an audience member at each stage of the dissembling of the stage to reassert the very protocols of distance from involvement we thought we were paying to see dispelled" (Read, Expanded Field 13). In other words, audiences seek the safety and even isolation of being a spectator who is well separated from the events on stage, while at the same time craving forms of community and involvement. A livecast with a Twitter feed seems to be the perfect solution for this schizophrenic state of mind. Where audiences in the theatre are immunised, safe in the knowledge that they will not have to participate, guided by social convention through the quasi-communitarian experience, here they are 'hyperimmunised,' as I would call it. They are alone at home, having to fear no public or 
social interaction at all while still being able to at least feel part of some kind of collective or community. However, the pleasure of hyper-immunisation does not last long.

'How do you clap over Twitter?' inquired some at the end of the six-hour live-streaming of Forced Entertainment's Speak Bitterness from Hebbel am Ufer in Berlin on Saturday night. Somebody else demanded to know the location of the post-show bar. A virtual one, of course. (Gardner, "Bitterness")

Right after the show people began to long for the post show drink at the bar, possibly with friends, bringing back social interaction, escaping loneliness. The state of hyper-immunisation grants all the safety and distance that the privacy of one's home has to offer, but tellingly spectators still seek the very mechanisms of social interaction, which void the safety net of isolation.

This can be related to wider social developments in the realms of media use and virtual culture. Josephine Machon has proffered that, for instance, the success of immersive theatre practices over the past decade is largely due to audiences seeking genuine human contact and the thrill of the unknown (cf. Immersive 29-31). It is not far-fetched to see a growing trend of isolation and even growing loneliness in an age in which a majority of social exchanges for many people consist of typing something into an electronic device. Game studies have even heralded the coming of a complete virtual future, in which users will be able to immerse themselves complete in virtual spaces (cf. Bainbridge). In short, virtuality, virtual social interaction and at the same time sentiments of isolation become increasingly prominent. Theatre is not only a counter-draft to virtuality, but it is a space where non-virtual exchange and experience in a public setting is possible. Read, consequently, has highlighted it as the 'last human venue:'

\footnotetext{
It was already clear that there was to be no 'post-human,' humans in their diversity were too canny and cussed for that, but rather a more prosaic evolutionary adaptation of circumstance: to the gradual increase in appetite for affect in the screen-world of virtuality, the nostalgia for agency and the consequent retooling for action over reaction, the rediscovery of the potential for pleasure and increased states of excitation that blurred the boundary between suffering and satisfaction. It was performance in general and theatre in particular that had, largely unnoticed, provided the playful mechanism of the measure of human value and a convivial venue through which, and within which, such exploration could be more or less safely carried out. Some tickets had also to be sold. (Read, Human Venue 2)
}

The unique ability of theatre in terms of a nostalgia for agency in a space of copresence, makes it a counter-draft to the world of virtuality. In a livecast and Twitter environment, however, this ability is lost. Theatre cannot provide agency 
or even the fragment of community that might be found in physical co-presence. The audience which seeks both, safe dividing lines and inclusion ends up more isolated and even less involved, despite the ability to comment. As Read has remarked dryly: "We are all onanists now" (Expanded Field 14).

The spectator in the theatre is not alone, the way he is in front of the TV; he is not watching a finished work of art or a film; instead, the spectator is part of the event, existing within the same space and time. Active presence in a common situation. (Malzacher 124)

It is a truism that the concept of 'the audience' as a community has been thoroughly and fruitfully deconstructed (cf. Blau and Bennet). However, the "active presence in a common situation" that Malzacher describes is still frequently important to the creation of performance. During livecasts, the spatial distance forbids such creation, or, rather, it shifts it into the virtual sphere. After Speak Bitterness, Gardner remarked: "The responses to FEspeaklive on twitter are not just responses but a kind of parallel performance” (Gardner, "Tweet Bitterness"). The act of co-creation took place over Twitter and it was not the performance event taking place in a theatrical venue that mattered, but the performance, which evolved in the virtual space, somewhere between the livebroadcast, Twitter and one's supper. If the term community is doubtful for a theatrical event, then it should be even more doubtful in the virtual space (despite its ubiquitous use). Nonetheless, both Gardner (cf. "Tweet Bitterness") and Haydon believe that in such events community can unfold. Whether this is any meaningful kind of community remains questionable. After all, as has been said, the limited amount of characters for a statement and the nature of the tweets (mostly statements, little discussion) undermine the idea of a community where, I would argue, exchange has to be dialogical and not monological. Perhaps this is due to the medium twitter. A more successful experiment with exchanges during a performance was made by Exeunt magazine during the livecast of And On The Thousandth Night (2014), where a live blog was established and a whole number of users could not only repeat phrases but write longer comments and enter into a dialogical exchange. Haydon remarked that

during that epic, hallucinogenic period, Exeunt magazine offered a Durational Criticism blog, and Twitter was ablaze with the online audience exclaiming, laughing together and repeating great lines to each other. For six hours it felt like we were very much a community.

Although I would still want to critically assess Haydon's conception of 'community,' it is remarkable that in the medium of a blog, which gives more room and is nowhere near as fast-paced as Twitter an exchange can develop. The audience is 
thus given a voice in the very literal sense and consequently even transcends Rancière's conception of emancipation.

\section{Conclusion}

The politics of livecasting depend very much on the individual format. As this paper has elaborated, livecasting of performances to cinemas proves to be a double-edged sword. The promise of community contains both a moment of inclusion and a moment of exclusion, which highlights the exclusivity of the event and the theatregoers. Aesthetic considerations must lead to similar ambiguity. On the one hand, livecasting produces images and angles that are impossible in the theatre and it enables viewers to see close-ups of the performance, on the other hand the camera takes away agency from the viewer. It becomes an active agent and shapes the performance that the viewer in the cinema sees. It thus creates a second performance that may be very much like the one in the theatre, but not the same. Consequently, it is closer to cinema than it is to theatre.

Performances that make use of Twitter in order to engage audiences and establish some kind of community must also be regarded critically in terms of their politics. As the examples of FE's livecasts and their respective Twitter feeds show, the promise of inclusion and community turns out to be a promise of hyper-immunisation or even isolation. Crucially, this is due to a lack of dialogue and meaningful exchange between viewers that would go beyond the simple repetition of favourite lines or statements as to one's whereabouts or circumstances of watching. More promising are projects such as blogs that allow for a more thorough exchange.

Finally, in the light of the considerations above, I want to argue that livecasts of the interactive type should also be seen as a separate kind of art form that is related to theatre but which is not the same. The heavy use of media, the interactive components, and the spatial distance turn it into an artwork in its own right. Gardner has hinted toward this:

What was happening on Twitter became a parallel performance to what was happening on stage in Germany, not just a response, but something that was creative and beautiful in its own right, and created together. Somebody else observed that anyone looking at the Twitter stream now would see something "like frozen performance debris." As @WHoustoun observed afterwards: "the internet finally made proper sense to me last night with \#FESpeakLive something calming and communal." (Gardner, "Bitterness")

It is indicative that @WHouston should state that the internet made sense to him, and not theatre or the performance. The livecasts of FE are a mixture of different 
media, places and experiential circumstances and must thus be considered as artworks and art forms of their own which are only loosely related to the original performance in a theatrical venue. The question is whether such performances will deliver an extra value or whether they further isolation and undermine the very principles that set theatre apart from other art forms and make it attractive. Barker is correct in pointing out that livecasts have yet received too little academic attention and he is also right in stressing that there is too little dialogue between the disciplines that can make useful contributions to the subject, such as Game and Media Studies, Theatre Studies or Communication Studies (cf. 41). In order to come to grips with this new phenomenon, new terminology and interdisciplinary research are needed. This is so for two reasons: first, because it seems likely thatif anything-the use of media and interactive platforms will increase in the decades to come, and secondly because the digital realm of communication (maybe even community) and discourse can fundamentally change and enrich theatrical practice. "Obviously interactive theatre is different to a sit-down performance [...] but nonetheless, the idea that the passive viewer may very soon be handed the keys to the editing suite and be able to call their own shots is a seductive vision indeed" (Haydon). Companies such as Game Theory or immersive companies like Punchdrunk have been experimenting with higher degrees of involvement. However, as Haydon stresses, none have achieved this complete agency so far. Yet it is not unlikely that with technological advances this will be possible soon. Theatre Studies and other disciplines must be prepared for this day.

\section{Works Cited}

Anon. "And on the Thousandth Night: A Multi-Authored, Durational Writing Project Responding Live to the Performance of and on the Thousandth Night." Exeunt Magazine, 2014. Web. 23 March 2015.

Bainbridge, William. The Virtual Future. London: Springer, 2011. Print.

Barker, Martin. Live to Your Local Cinema: The Remarkable Rise of Livecasting. Basiongstoke: Palgrave Macmillan, 2013. Print.

Benjamin, Walter. The Work of Art in the Age of Mechanical Reproduction [1936]. Trans. J.A. Underwood. Penguin Great Ideas. London: Penguin, 2008. Print.

Bennett, Susan. Theatre Audiences: A Theory of Production and Reception. London: Routledge, 1990. Print.

Blau, Herbert. The Audience. Parallax Series: Revisions of Culture and Society. Baltimore: Johns Hopkins University Press, 1990. Print.

Dobson, A. E. “Live to Your Local Cinema-Michael Barker.” Exeunt Magazine, 2013. Web. 24 March 2015.

Etchells, Tim. "Speak Bitterness: Our Catalogue of Confessions." The Guardian Online, 2014. Web. 23 March 2015. 
Gardner, Lyn. “Tweet Bitterness: How Forced Entertainment Took over Twitter.” The Guardian Online, 2014. Web. 23 March 2015.

---. “Lyn Gardner’s Top Ten Theatre of 2014b.” The Guardian Online, 2014. Web. 23 March 2015. Haydon, Andrew. “Coney’s No Island: Could Live Streamed Theatre Let Audiences Call the Shots?" Guardian Theatre Blog, 2014. Web. 23 March 2015.

Kotler, Philip. Standing Room Only: Strategies for Marketing the Performing Arts. Boston: Harvard Business School Press, 1997. Print.

Machon, Josephine. (Syn)Aesthetics: Redefining Visceral Performance. Basingstoke: Palgrave, 2009. Print.

---. Immersive Theatres: Intimacy and Immediacy in Contemporary Performance. London: Palgrave, 2013. Print.

Malzacher, Florian. "There Is a Word for People Like You: Audience-the Spectator as Bad Witness and Bad Voyeur." Not Even a Game Anymore: The Theatre of Forced Entertainment. Eds. Judith Helmer and Florian Malzacher. Berlin: Alexander Verlag, 2004. Print.

Rancière, Jacques. The Emancipated Spectator. London: Verso, 2009. Print.

---. The Politics of Aesthetics: The Distribution of the Sensible. London: Continuum, 2011. Print.

Read, Alan. Theatre, Intimacy \& Engagement: The Last Human Venue. Studies in International Performance. Eds. Reinelt, Janelle and Brian Singleton. 1. publ. ed. Basingstoke: Palgrave Macmillan, 2008. Print.

---. "From Theatre \& Everyday Life to Theatre in the Expanded Field: Performance between Community and Immunity." Journal of Contemporary Drama in English 2.1 (2014): 8-25. Print.

Stadelmaier, Gerhard. “Verdammte Kamera.” Frankfurter Allgemeine Zeitung, 2014. Web. 23 March 2015.

Tobler, Andreas. “Gratis Theater Für Alle?“ Basler Zeitung Online, 2014. Web. 20 March 2015.

\section{Performances}

And on the Thousandth Night. Dir. Tim Etchells, Forced Entertainment. Culturgest, Lisbon.

22 March 2014. Performance.

Frankenstein. Dir. Danny Boyle. Royal National Theatre, London. 21 Oct. 2014. Performance. King Lear. Dir. Sam Mendes. Royal National Theatre, London. 01 May 2014. Performance. Quizoola24!. Dir. Tim Etchells, Forced Entertainment. Millenium Galleries, Sheffield. 21-22 Nov. 2014. Performance.

Speak Bitterness. Dir. Tim Etchells, Forced Entertainment. Hebbel Am Ufer, Berlin. 18 Oct. 2014. Performance. 